\title{
MÉTODOS DE SEMEADURA E APLICAÇÃO DE 2,4-D NA FORMAÇÃO DE BRAQUIÁRIA RUZIZIENSIS PARA PLANTIO DIRETO
}

\author{
Suzete Fernandes Lima ${ }^{1}$, Paulo César Timossi ${ }^{2}$, Dieimisson Paulo Almeida ${ }^{3}$ \\ ${ }^{1}$ Doutoranda em Ciências Agrárias - Agronomia pelo Instituto Federal Goiano, Câmpus de Rio Verde - GO, \\ Brasil.E-mail: suzete.lima@yahoo.com.br \\ ${ }^{2}$ Professor na Universidade Federal de Goiás - Regional Jataí. Rodovia BR 364, Km 192, Setor Parque \\ Industrial, 3800, Caixa postal 03, 75801-615, Jataí - GO, Brasil. \\ ${ }^{3}$ Doutorando em Agronomia - Produção Vegetal na UNESP - Câmpus de Jaboticabal - SP, Brasil.
}

RESUMO: O sucesso de sistemas conservacionistas como o plantio direto depende da adequada cobertura do solo durante todo o ano, mediante a utilização de espécies adaptadas com produção de massa vegetal no período outono-inverno. Com este propósito as espécies pertencentes ao gênero Urochloa tem se destacado, em virtude de sua rusticidade e tolerância ao déficit hídrico. Almejando a cobertura do solo para o sistema plantio direto, objetivou-se avaliar o estabelecimento da Urochloa ruziziensis em três métodos de semeadura e a influência da aplicação do herbicida 2,4-D. O delineamento adotado foi o de blocos casualizados em arranjo fatorial 3 x 2, no qual o fator A foi composto por três métodos de semeadura (a lanço, a lanço com incorporação e em linha) e o fator B pela aplicação ou não aplicação do herbicida 2,4-D (419 g de e.a. ha-1). Foram realizadas avaliações aos 30, 60, 90, 120 e 245 DAS para determinação da produção de fitomassa e cobertura do solo. Conclui-se que a aplicação de herbicida não promove diferença de produção de massa vegetal para plantio direto e, os métodos de semeadura com incorporação de sementes se destacam em relação à semeadura a lanço.

Palavras-chave: Cobertura vegetal. Integração lavoura-pecuária. Supressão de plantas daninhas. Urochloa sp.

\section{SOWING METHODS AND HERBICIDE APPLICATION IN THE FORMATION OF BRACHIARIA RUZIZIENSIS FOR NO-TILL}

\begin{abstract}
The success of conservation systems such as no-till depends on adequate soil cover throughout the year, through the use of species adapted to dry mass production in the autumn-winter period. For this purpose the species belonging to the genus Urochloa has stood out by virtue of its hardiness and tolerance to drought. Aiming ground cover for no-till system, objective was to evaluate the establishment of Urochloa ruziziensis in three sowing methods and the need for herbicide application of 2,4-D herbicide. The study design was a randomized block with factorial arrangement $3 \times 2$, in wich factor A was composed of three sowing methods (sown without incorporation, sown with light incorporation and sown in rows) and factor B by the application and not applying herbicide 2,4-D (419 g de e.a. ha $\mathrm{h}^{-1}$ ). Evaluations were performed at 30,60, 90, 120 and 245 DAS to determine the biomass production and soil cover. It is concluded that the herbicide does not promote difference in dry mass production and the methods of sowing seeds incorporating stood out in relation of the distribution on the
\end{abstract}

Cultura Agronômica, Ilha Solteira, v.25, n.2, p.175-186, 2016 
soil surface.

Key words: Vegetal cover. Crop-livestock integration. Weed suppression. Urochloa sp.

\section{INTRODUÇÃO}

A semeadura de gramíneas forrageiras após o cultivo da safra, em substituição ao pousio, se torna uma alternativa viável para a cobertura do solo e consecutivamente supressão de plantas daninhas, levando à diminuição do banco de sementes do solo ao longo dos anos (IKEDA et al., 2007; NOCE et al., 2008; NUNES et al., 2006; SEVERINO et al., 2006; TIMOSSI et al., 2007). A presença de cobertura vegetal sobre o solo em quantidade adequada para o sistema plantio direto, com a utilização de gramíneas forrageiras também favorece a implantação do sistema integração lavoura-pecuária, já que tais espécies proporcionam massa vegetal suficiente para serem disponibilizadas na alimentação animal na entressafra.

Na região do Cerrado, a Urochloa ruziziensis (braquiária ruziziensis), tem se destacado para a formação de cobertura vegetal do solo, pois se mantém em crescimento durante a estação seca (MACHADO; ASSIS, 2010), além de ser facilmente controlada por herbicidas (BRIGHENTI et al., 2011). Também pode ser utilizada para a alimentação animal no período outono-inverno, atenuando o efeito da estacionalidade das forrageiras (VILELA et al., 2011) e destaca-se pela supressão de plantas daninhas (GIMENES et al., 2011). No estabelecimento inicial da braquiária a redução da competição, com a comunidade de plantas daninhas, pode potencializar a colonização da área pela forrageira, o que pode ser obtido com o uso de herbicidas seletivos (CARÁMBULA, 1996), como o 2,4-D.

O estabelecimento e o desenvolvimento de plantas constituem pontos relevantes para a formação de cobertura vegetal, que está diretamente ligado ao método e profundidade de semeadura. Em áreas de plantio direto tem-se várias pesquisas sobre o estabelecimento de forrageiras em consórcio com a cultura anual (BORGHI; CRUSCIOL, 2007; JAKELAITIS et al., 2004; JAKELAITIS et al., 2005), entretanto, em relação ao estabelecimento exclusivo da forrageira, visando a formação de cobertura vegetal em áreas de plantio direto carece de pesquisas. Desta forma, torna-se importante a identificação de práticas agrícolas e métodos de semeadura que favoreça a cobertura do solo em menor espaço de tempo, que seja eficiente na produção de fitomassa e supressão de plantas daninhas. Neste contexto, avaliou-se o estabelecimento da cobertura vegetal sobre o solo em áreas para plantio direto, sob diferentes métodos de semeadura de braquiária ruziziensis, com e sem aplicação do herbicida 2,4-D.

\section{MATERIAL E MÉTODOS}

A pesquisa foi realizada no sudoeste de Goiás, em Jataí, na Fazenda Escola da Universidade Federal de Goiás, nas seguintes coordenadas geográficas: 1755'31,78' S e $51^{\circ} 42^{\prime} 36,17^{\prime}$ ' N. O solo da área experimental é classificado como Latossolo Vermelho distroférrico, de textura argilosa (EMBRAPA, 2006). Segundo a classificação köppen, o clima da região é do tipo Aw, caracterizado por apresentar temperaturas anuais elevadas e 
regime pluviométrico definido pela ocorrência de duas estações: verão chuvoso e inverno seco. Os dados climatológicos do período de condução da pesquisa (Figura 1) foram obtidos na estação agrometeorológica do INMET (Instituto Nacional de Meteorologia), lotado a 1500 $\mathrm{m}$ da área experimental. Antes da semeadura da braquiária foram coletadas amostras de solo da camada de 0-20 cm, para análise química do solo (Tabela 1). A espécie avaliada como cobertura vegetal foi a Urochloa ruziziensis (braquiária ruziziensis), implantada em 30/03/2012 após a colheita da soja. A área experimental apresenta histórico de cultivo da sucessão soja/sorgo há pelo menos 5 anos, em plantio direto.

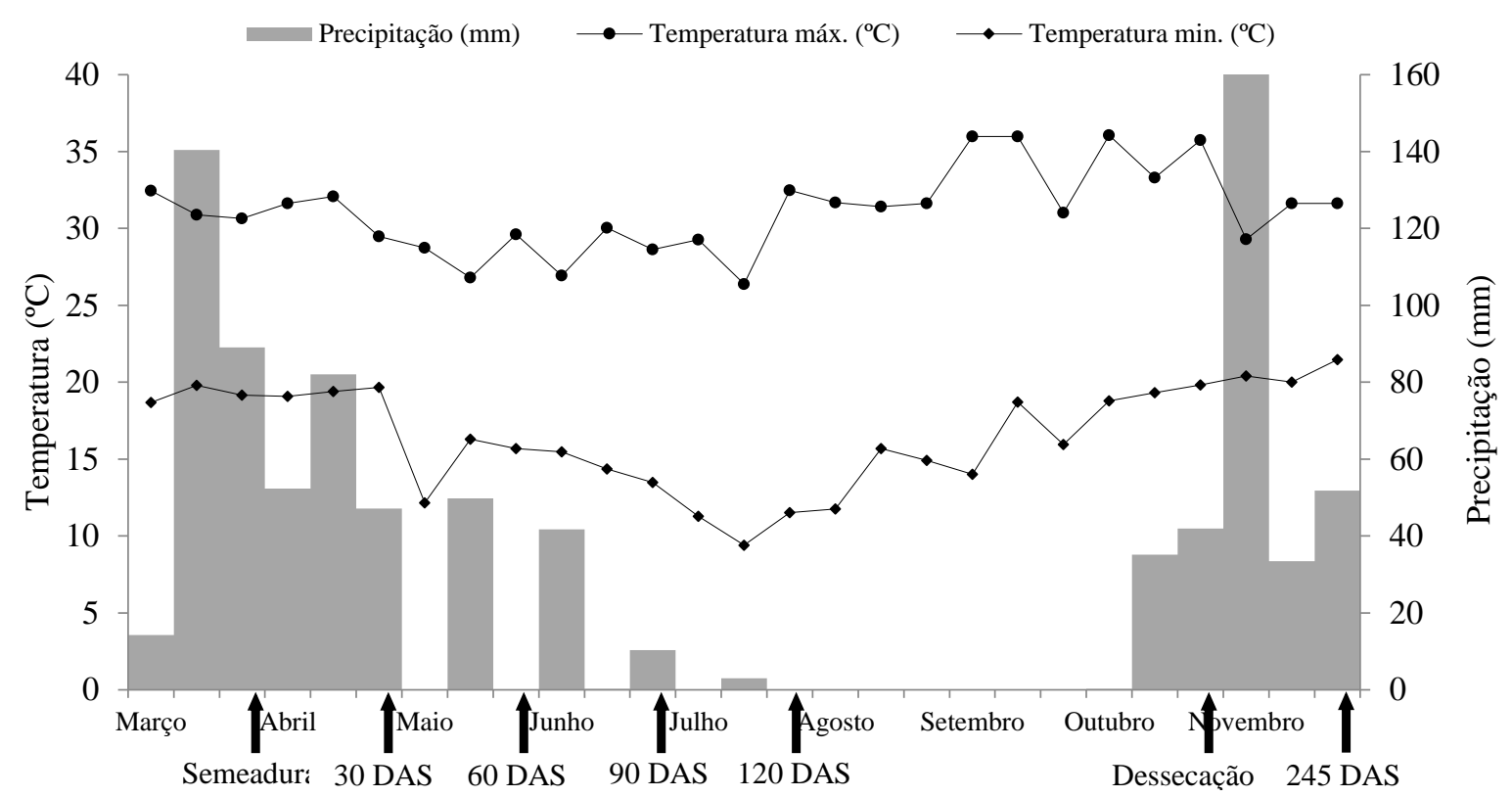

Figura 1. Médias de temperatura máxima e mínima do ar e total de precipitações, em decêndios, durante o período de condução do experimento.

Fonte: Dados da estação agrometeorológica do INMET coletado em 2012.

Tabela 1. Propriedades químicas da amostra de solo da área experimental.

\begin{tabular}{|c|c|c|c|c|c|c|c|c|c|}
\hline $\mathrm{pH}$ & $\mathrm{Al}$ & $\mathrm{Ca}$ & $\mathrm{Mg}$ & $(\mathrm{H}+\mathrm{Al})$ & K & $\mathrm{P}$ & CTC & SB & MO \\
\hline $\mathrm{H}_{2} \mathrm{O}$ & & $--\left(\mathrm{Cl}_{1}\right)$ & $\left.\mathrm{dm}^{-3}\right)$ & 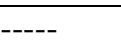 & $-(\mathrm{mg}$ & $\left.n^{-3}\right)-$ & $\left(\mathrm{Cmolcdm}^{-3}\right)$ & $(\%)$ & $\left(\mathrm{gKg}^{-1}\right)$ \\
\hline$\overline{5,4}$ & 0,15 & 2,30 & 0,87 & 6,01 & 145,0 & 6,12 & 9,55 & 3,54 & 36,24 \\
\hline
\end{tabular}

O delineamento experimental adotado foi o de blocos casualizados, com quatro repetições, dispostos num esquema fatorial $3 \times 2$, totalizando seis tratamentos. Onde o fator A foi composto por três métodos de semeadura (a lanço, a lanço com leve incorporação por grade niveladora 'fechada' e em linha) e o fator B pela aplicação e ausência de aplicação do herbicida 2,4-D (419 $\mathrm{g}$ de e.a. ha $\left.{ }^{-1}\right)$. A área de cada parcela experimental foi de $4 \mathrm{~m}$ de largura por $15 \mathrm{~m}$ de comprimento, totalizando $60 \mathrm{~m}^{2}$.

A taxa de semeadura de braquiária ruziziensis seguiu a recomendação de pontos de valor cultural (VC), onde foram utilizados 400 pontos de $\mathrm{VC} \mathrm{ha}^{-1}$ para a semeadura a lanço e a lanço incorporada e 240 pontos de $\mathrm{VC} \mathrm{ha}^{-1}$ para a semeadura em linha. Para as duas modalidades de semeadura a lanço, as sementes foram semeadas manualmente em área total.

Cultura Agronômica, Ilha Solteira, v.25, n.2, p.175-186, 2016 
No tratamento com incorporação foi realizada uma operação de gradagem leve com grade niveladora, na profundidade de $0,05 \mathrm{~m}$. Para a semeadura em linha, foram implantadas 8 linhas em cada parcela, espaçadas de $0,45 \mathrm{~m}$, com $0,05 \mathrm{~m}$ de profundidade, simulando a adoção de semeadora tratorizada.

A aplicação do herbicida 2,4-D foi realizada aos 60 dias após a semeadura (DAS) da braquiária ruziziensis, utilizando-se $419 \mathrm{~g}$ de ingrediente ativo por hectare e volume de calda de $200 \mathrm{~L} \mathrm{ha}^{-1}$, com pulverizador de pesquisa, com barras de quatro bicos e pontas DG 11002 , espaçadas em $0,5 \mathrm{~m}$, mantida à pressão constante por $\mathrm{CO}_{2}$. A aplicação foi realizada no período vespertino $(15: 00 \mathrm{~h})$, com temperatura do ar de $29,4^{\circ} \mathrm{C}$, umidade relativa do ar de $70 \%$ e umidade no solo a partir de $3 \mathrm{~cm}$ de profundidade.

Aos 30 e 60 DAS, determinou-se a composição específica das espécies de plantas presentes, além da densidade populacional em cada parcela experimental. A produção de massa vegetal proporcionada pela planta de cobertura foi avaliada aos 30, 60, 90 e 120 DAS. Para isto, as plantas foram cortadas rente ao solo, separadas em plantas de cobertura e plantas daninhas e levadas para secagem. Em ambas as avaliações, em cada parcela experimental, amostraram-se três quadros de 0,50 x 0,50 m (0,25 $\left.\mathrm{m}^{2}\right)$, lançados aleatoriamente.

A porcentagem de cobertura vegetal sobre o solo, proporcionada pela braquiária ruziziensis e pelas espécies de plantas daninhas, foi realizada aos 30, 60, 90 e 120 DAS pela técnica do intercepto de linha (BROWER; ZAR, 1984). Na técnica do intercepto de linha foi utilizada uma corda com 100 intervalos, espaçados de $0,05 \mathrm{~m}$, somando $5 \mathrm{~m}$ de comprimento. Esta avaliação foi feita em três pontos aleatórios em cada parcela experimental, nos quais foram contados os intervalos que apresentavam cobertura vegetal pela planta de cobertura e pelas plantas daninhas.

Em 31/10/2012 (215 DAS), realizou-se a dessecação da área experimental, com o herbicida glyphosate a $1680 \mathrm{~g}$ de equivalente ácido por hectare. Aos 245 DAS realizou-se a coleta da massa vegetal da braquiária ruziziensis, com o uso de um quadro de 0,5 x 0,5 m $\left(0,25 \mathrm{~m}^{2}\right)$, em três pontos aleatórios em cada parcela, para determinação de massa seca proporcionada pela braquiária ruziziensis. Neste período, também foi realizada a avaliação da porcentagem de cobertura vegetal sobre o solo.

Os dados de estande de plantas, produção de massa seca e porcentagem de cobertura sobre o solo foram submetidos à análise de variância e posteriormente, quando necessário, a comparação de médias pelo teste de Tukey a 5\% de significância (BANZATTO; KRONKA, 2006).

\section{RESULTADOS E DISCUSSÃO}

As plantas daninhas identificadas na área experimental foram: Digitaria horizontalis (capim-colchão), Eleusine indica (capim-pé-de-galinha), Pennisetum setosum (capimcustódio), Chamaesyce hirta (erva-de-santa-luzia), Bidens pilosa (picão-preto) e Conyza sp. (buva).

Cultura Agronômica, Ilha Solteira, v.25, n.2, p.175-186, 2016 
De posse das informações da composição específica da comunidade infestante, realizada aos 30 e 60 DAS, agrupou-se as espécies de plantas daninhas em monocotiledôneas e eudicotiledôneas (Figura 2), indicando equilíbrio entre os grupos.

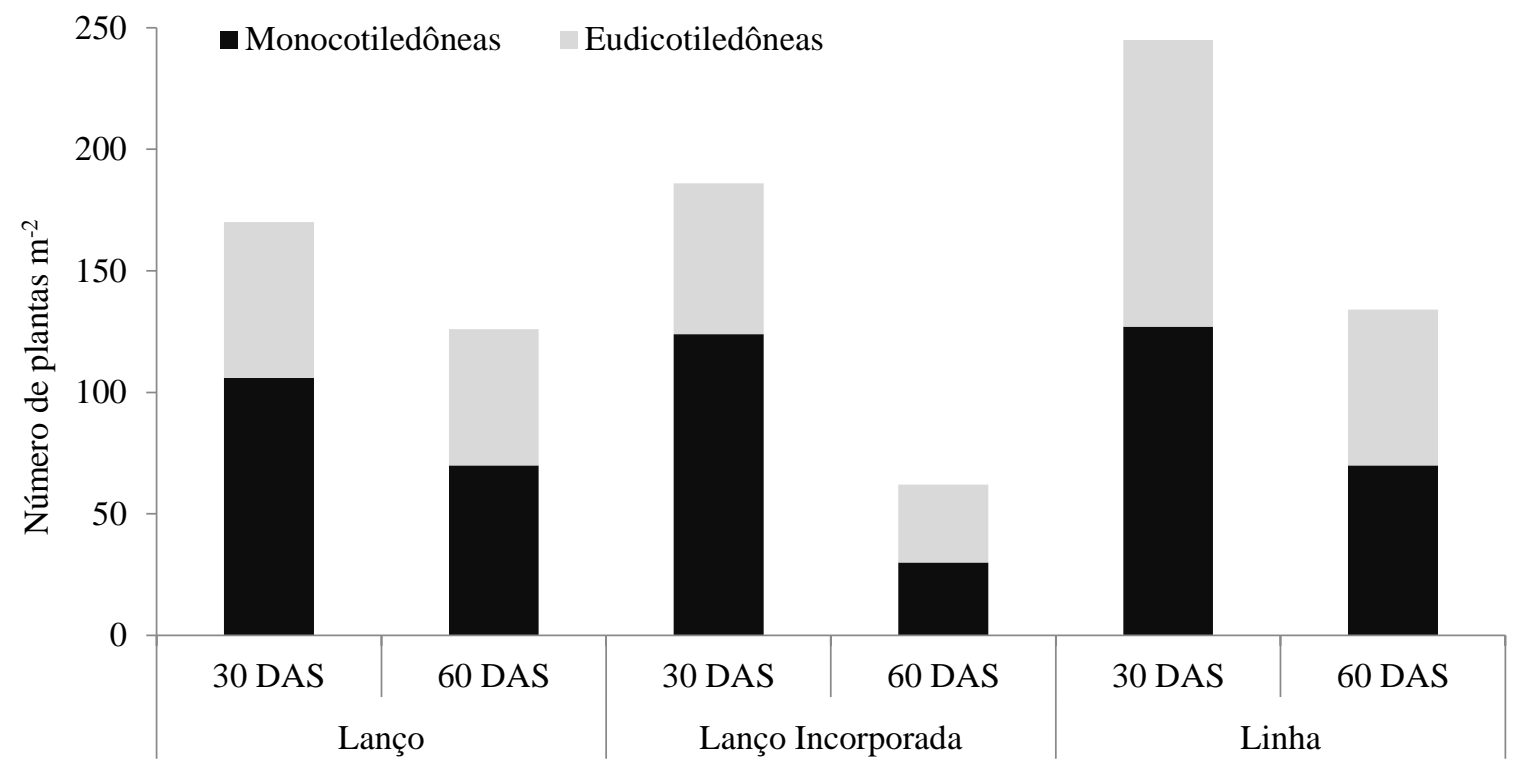

Figura 2. Número de plantas daninhas monocotiledôneas (M) e eudicotiledôneas (D) por $\mathrm{m}^{2}$ presentes nos três métodos de semeadura da braquiária ruziziensis aos 30 e 60 dias após a semeadura (DAS).

Nos três métodos de semeadura nota-se um decréscimo acentuado do número de plantas dos 30 DAS para os 60 DAS, sendo indicativo da possível supressão de plantas daninhas quando em convivência com a braquiária ruziziensis.

Quanto aos métodos de semeadura de braquiária, verifica-se maior número de plantas emergidas no método de semeadura a lanço incorporada, o qual não diferiu do método de semeadura em linha (Tabela 2). Segundo Garcia et al. (1998), a incorporação de sementes melhora a sua distribuição no perfil do solo, proporciona maior proteção e contato das sementes com o solo, o que favorece a germinação e fixação do sistema radicular no solo. Já a semeadura a lanço proporcionou menor número de plantas emergidas. Segundo Pitelli e Durigan (2001), sementes depositadas sobre o solo estão susceptíveis à ação de predadores, como pássaros e roedores e à ação de microorganismos do solo.

Tabela 2. Estande de plantas de braquiária ruziziensis (plantas $\mathrm{m}^{-2}$ ), determinado aos 30 e 60 dias após a semeadura (DAS).

\begin{tabular}{lcc}
\hline Método de Semeadura & $30 \mathrm{DAS}$ & $60 \mathrm{DAS}$ \\
\hline Lanço & $13 \mathrm{~b}^{1}$ & $15 \mathrm{~b}$ \\
Lanço Incorporada & $22 \mathrm{a}$ & $23 \mathrm{a}$ \\
Linha & $19 \mathrm{ab}$ & $18 \mathrm{ab}$ \\
\hline DMS & 7,42 & 4,95 \\
\hline $\mathrm{CV}(\%)$ & 30,88 & 19,73 \\
\hline
\end{tabular}

${ }^{1}$ Médias seguidas pela mesma letra , na mesma coluna, não diferem entre si, pelo teste de Tukey a $\mathrm{P}<0,05$.

Cultura Agronômica, Ilha Solteira, v.25, n.2, p.175-186, 2016 
Para a formação de pastagens são recomendadas de 15 a 20 plantas de braquiária por $\mathrm{m}^{2}$ (VALLE et al., 2001). Desta forma, os três métodos de semeadura proporcionaram número de plantas adequadas à formação da braquiária ruziziensis.

O método de semeadura a lanço proporcionou menor produção de massa vegetal (Tabela 3), o que pode estar relacionado à menor densidade de plantas de braquiária e à maior competição com as plantas daninhas, corroborando com os resultados obtidos por Lima et al. (2014), que verificaram maior estande e produção de massa vegetal em braquiárias estabelecidas com métodos de semeadura com incorporação de sementes. No entanto, os três métodos de semeadura proporcionaram massa vegetal superior ao recomendado para o plantio direto, de $6000 \mathrm{~kg} \mathrm{ha}^{-1}$ (ALVARENGA et al., 2001). A alta produção de fitomassa por plantas de cobertura é um indicativo do potencial de utilização desta espécie no período de outono/inverno (entressafra), refletindo na cobertura vegetal sobre o solo e supressão de plantas daninhas.

Tabela 3. Valores de F, DMS, coeficientes de variação (CV\%), aplicado às médias de produção de massa seca da braquiária ruziziensis, aos 30, 60, 90, 120 e 245 dias após a semeadura (DAS).

\begin{tabular}{lllllll}
\hline \multirow{2}{*}{} & \multirow{2}{*}{ Variáveis } & \multicolumn{4}{l}{ Massa seca de braquiária ruziziensis $\left(\mathrm{kg} \mathrm{ha}^{-1}\right)$} \\
\cline { 3 - 7 } & Herbicidas $(\mathrm{H})$ & $3,86^{\mathrm{ns}}$ & $0,00^{\mathrm{ns}}$ & $1,79^{\mathrm{ns}}$ & $0,93^{\mathrm{ns}}$ & $1,23^{\mathrm{ns}}$ \\
\hline \multirow{2}{*}{$\mathrm{F}$} & Semeadura $(\mathrm{S})$ & $12,46^{*}$ & $6,77^{*}$ & $2,41^{\mathrm{ns}}$ & $10,74^{*}$ & $6,90^{*}$ \\
& $\mathrm{H}$ x S & $1,54^{\mathrm{ns}}$ & $0,84^{\mathrm{ns}}$ & $0,91^{\mathrm{ns}}$ & $2,68^{\mathrm{ns}}$ & $0,46^{\mathrm{ns}}$ \\
\hline \multirow{2}{*}{ Herbicida $(\mathrm{H})$} & Com & 242 & 2378 & 6702 & 7437 & 6962 \\
& Sem & 200 & 2389 & 7470 & 7902 & 7428 \\
\hline DMS & & 47 & 429 & 1231 & 1035 & 900 \\
\hline \multirow{2}{*}{ Semeadura } & Lanço & $146 \mathrm{~b}^{1}$ & $1908 \mathrm{~b}$ & 6242 & $6165 \mathrm{~b}$ & $6142 \mathrm{~b}$ \\
& Lanço incorporada & $265 \mathrm{a}$ & $2799 \mathrm{a}$ & 7525 & $8278 \mathrm{a}$ & $7689 \mathrm{a}$ \\
\hline DMS & Linha & $255 \mathrm{a}$ & $2495 \mathrm{ab}$ & 7595 & $8670 \mathrm{a}$ & $7845 \mathrm{a}$ \\
\hline CV $(\%)$ & 70 & 643 & 1843 & 1549 & 1348 \\
\hline
\end{tabular}

${ }^{1}$ Médias seguidas pela mesma letra, na mesma coluna, não diferem entre si, pelo teste de Tukey a $\mathrm{P}<0,05$.

Jakelaitis et al. (2005) avaliando a semeadura em linha e a lanço de Brachiaria brizantha em consorcio com o milho, constataram que a semeadura em linha propiciou estabelecimento inicial mais eficiente da forrageira e, maior potencial na supressão de plantas daninhas. Também, verificaram menor vigor da forrageira, em decorrência do baixo contato das sementes com o solo, na semeadura a lanço. Pariz et al. (2010) avaliando os métodos de semeadura a lanço e em linha, em quatro espécies de braquiária (Urochloa brizantha, Urochloa decumbens, Urochloa ruziziensis e capim mulato II - hibrido de Urochloa sp.) verificaram que somente para a Urochloa brizantha houve diferença de produção em decorrência do método de semeadura.

A aplicação do herbicida 2,4-D não promoveu diferença de produção e cobertura do solo em nenhum dos períodos avaliados (Tabela 3, 4 e 5). Desta forma, pode-se afirmar, para Cultura Agronômica, Ilha Solteira, v.25, n.2, p.175-186, 2016 
as condições da presente pesquisa, que não há necessidade de aplicação de herbicidas no estabelecimento da braquiária ruziziensis em áreas de plantio direto, pois a mesma possui potencial para vencer a competição com as plantas daninhas e se estabelecer na área. Ao controlar as plantas daninhas eudicotiledôneas o 2,4-D reduz a competição, da braquiária ruziziensis com a comunidade infestante de plantas daninhas, pelos recursos do meio, como água, luz, nutrientes, espaço, assim a forrageira pode ter maior crescimento e produção de massa seca.

Tabela 4. Valores de F, DMS, coeficientes de variação (CV\%), aplicado às médias de porcentagem de cobertura total do solo, aos 30, 60 e 90 dias após a semeadura (DAS).

\begin{tabular}{|c|c|c|c|c|}
\hline & \multirow{2}{*}{ Variáveis } & \multicolumn{3}{|c|}{ Cobertura vegetal total (\%) } \\
\hline & & $30 \mathrm{DAS}$ & $60 \mathrm{DAS}$ & 90 DAS \\
\hline \multirow{3}{*}{$\mathrm{F}$} & Herbicidas $(\mathrm{H})$ & $1,19^{\mathrm{ns}}$ & $1,51^{\mathrm{ns}}$ & $2,72^{\mathrm{ns}}$ \\
\hline & Semeadura (S) & $9,07^{*}$ & $55,91^{*}$ & $2,05^{\mathrm{ns}}$ \\
\hline & $\mathrm{H} \times \mathrm{S}$ & $1,29^{\mathrm{ns}}$ & $2,29^{\mathrm{ns}}$ & $3,18^{\mathrm{ns}}$ \\
\hline \multirow{2}{*}{ Herbicida $(\mathrm{H})$} & Com & 38,4 & 81,9 & 99,5 \\
\hline & Sem & 40,8 & 84,0 & 99,9 \\
\hline DMS & & 4,7 & 3,7 & 0,6 \\
\hline \multirow{3}{*}{ Semeadura } & Lanço & $33,2 b^{1}$ & $70,7 \quad b$ & 99,3 \\
\hline & Lanço incorporada & 42,7 a & 86,8 a & 99,9 \\
\hline & Linha & 43,3 a & 91,6 a & 100,0 \\
\hline DMS & & 7,1 & 5,5 & 0,9 \\
\hline $\mathrm{CV}(\%)$ & & 13,3 & 4,9 & 0,7 \\
\hline
\end{tabular}

${ }^{1}$ Médias seguidas pela mesma letra, na mesma coluna, não diferem entre si, pelo teste de Tukey a $\mathrm{P}<0,05$.

Tabela 5. Valores de F, DMS, coeficientes de variação (CV\%), aplicado às médias de porcentagem de cobertura do solo pela braquiária ruziziensis, aos 30, 60, 90 e 120 dias após a semeadura (DAS).

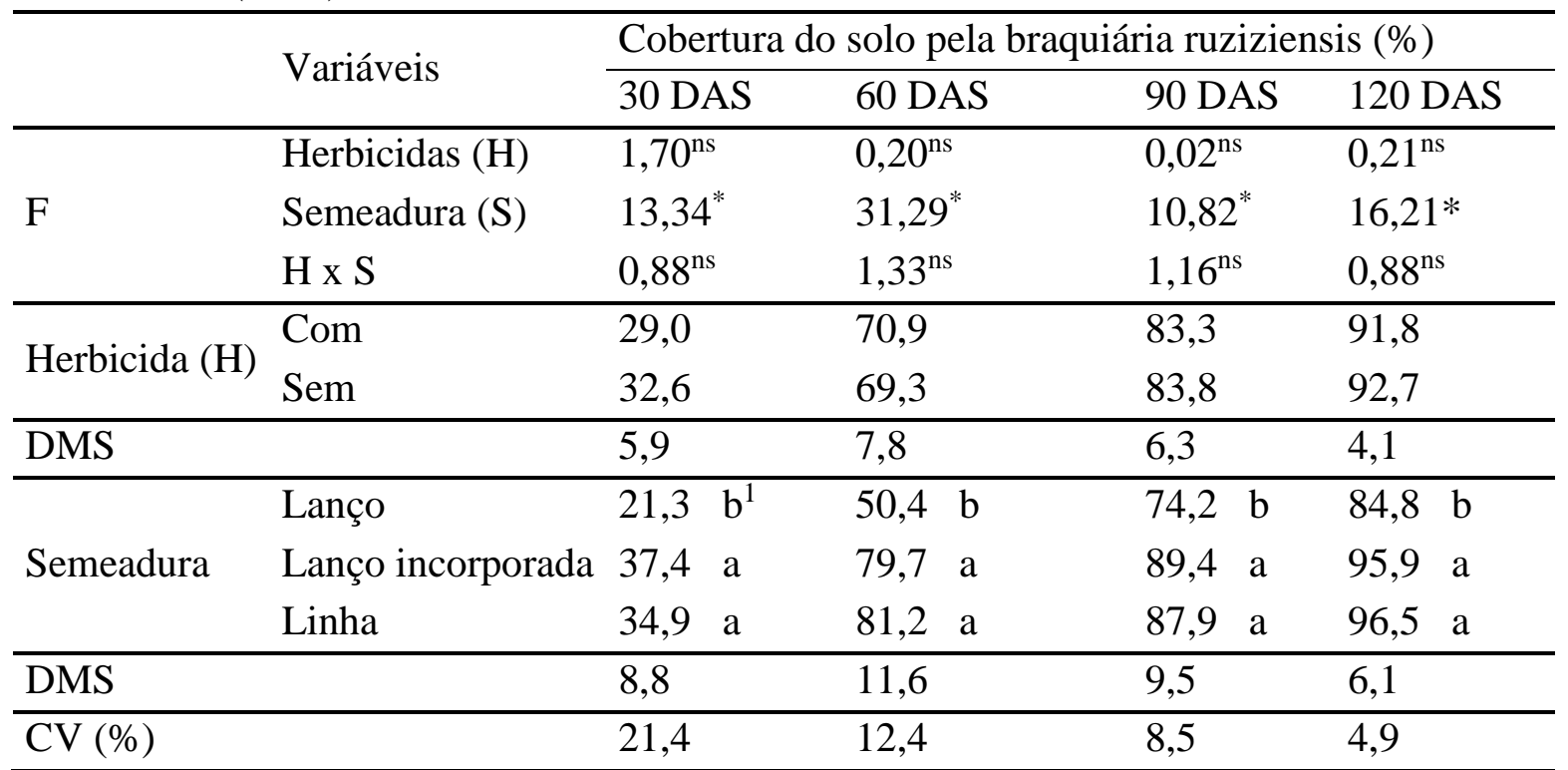

${ }^{1}$ Médias seguidas pela mesma letra, na mesma coluna, não diferem entre si, pelo teste de Tukey a $\mathrm{P}<0,05$.

Cultura Agronômica, Ilha Solteira, v.25, n.2, p.175-186, 2016 
Aos 30 e 60 DAS, a cobertura total do solo foi superior no método de semeadura em linha e a lanço incorporada, o que está relacionado à maior densidade de plantas e produção de massa seca da braquiária ruziziensis nestes métodos de semeadura. Aos 90 DAS não há diferença estatística entre os métodos de semeadura quanto à cobertura total do solo (Tabela 4), após o crescimento a forrageira proporcionou cobertura ao solo, mesmo no método de semeadura com menor densidade de plantas. Aos 120 DAS obteve-se $100 \%$ de cobertura sobre o solo nos três métodos de semeadura. Neste período, a braquiária ruziziensis já havia desenvolvido perfilhamento contribuindo para a total cobertura do solo. Aos 245 DAS, 30 dias após a dessecação da braquiária ruziziensis, obteve-se $100 \%$ de cobertura uniforme do solo nos três métodos de semeadura. A ocorrência do acamamento da palhada contribuiu para a uniformização da cobertura sobre o solo em todas as formas de semeadura.

As semeaduras a lanço com incorporação e em linha não diferiram estatisticamente entre si, apresentando porcentagem de cobertura do solo superior ao método de semeadura a lanço (Tabela 5). É provável que a menor porcentagem de cobertura do solo, na semeadura a lanço, esteja relacionada à menor densidade de plantas de braquiária (Tabela 2) necessitando, assim, de maior período para cobrir totalmente o solo. De acordo com Gimenes et al. (2011), a maior ocupação da área pela espécie forrageira promove maior competição por recursos do meio, sendo mais eficiente na supressão de plantas daninhas. De acordo com Jakelaitis et al. (2005), a maior porcentagem de cobertura do solo pela braquiária favorece a interceptação de luz pelo dossel da forrageira, limitando este recurso para o desenvolvimento das plantas daninhas.

Os métodos de semeadura a lanço incorporada e em linha proporcionaram desenvolvimento semelhante durante todo o período de avaliação. Enquanto que o método de semeadura a lanço, desde início, promoveu menor produção de massa seca (Figura 3), o que pode estar relacionado a menor densidade de plantas $\mathrm{m}^{-2}$.

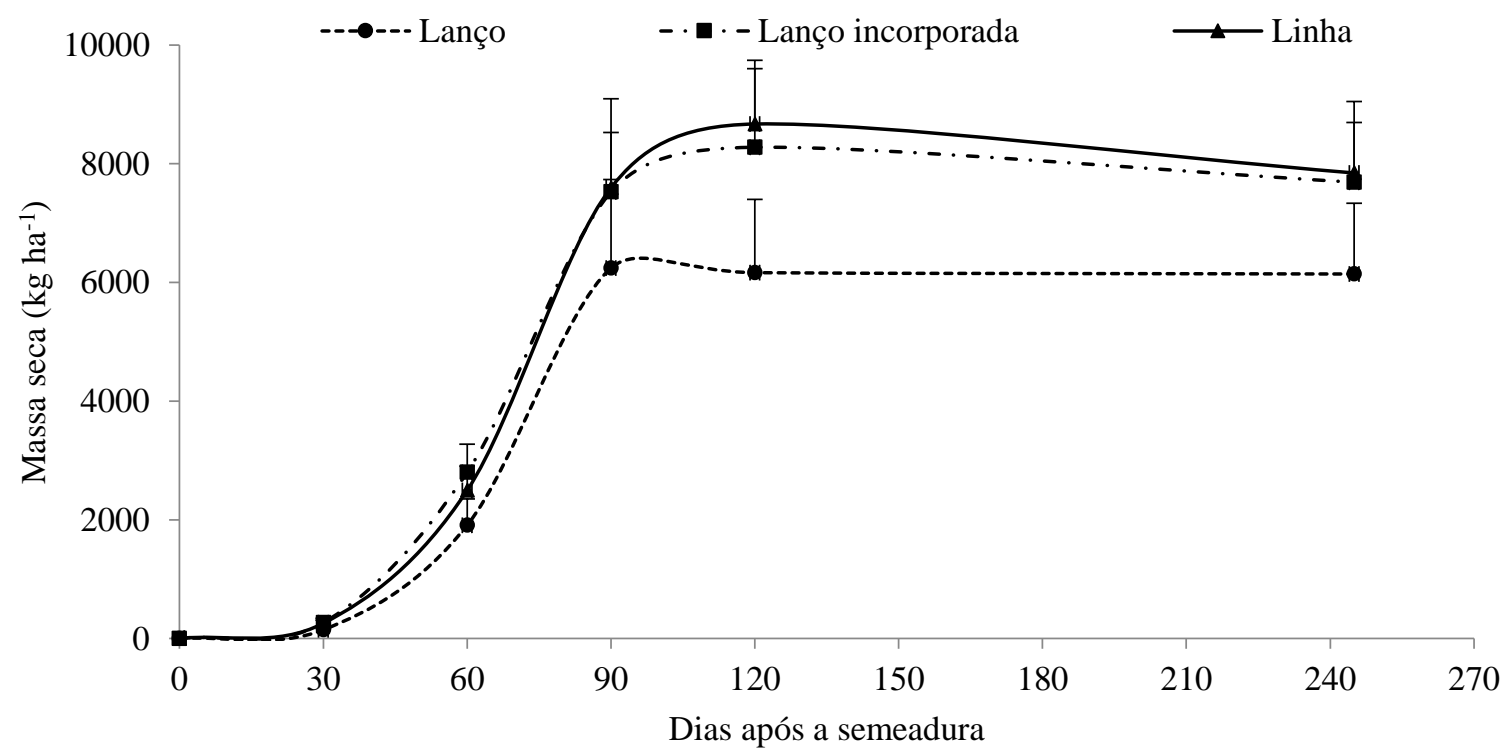

Figura 3. Produção de massa seca da Urochloa ruzizensis em função do tempo de crescimento (30, 60, 90, 120 e 245 DAS), em função do método de semeadura. 
No período inicial de desenvolvimento, até os 60 DAS, a braquiária apresentou baixo acúmulo de massa seca. Após este período, o crescimento é acelerado, obtendo-se alta produção de fitomassa, caracterizando o estabelecimento da braquiária ruziziensis na área. A baixa produção de massa seca da braquiária ruziziensis, até os 60 DAS, também foram constatadas por Menezes e Leandro (2004) e Timossi et al. (2007). Nesta pesquisa, o desenvolvimento inicial da braquiária foi beneficiado pelas condições climáticas favoráveis, não restringindo o desenvolvimento das plantas. Pode-se verificar também, aumento no acúmulo de massa vegetal até os 120 DAS. Após este período, passa a ocorrer estabilidade de acumulo de massa seca, o que está ligado ao desenvolvimento da braquiária, que após cobrir totalmente o solo tende a se manter estável durante o período avaliado.

\section{CONCLUSÃO}

1. Os métodos de semeadura com incorporação de sementes se destacam em relação ao método de semeadura a lanço sem incorporação no estande e produção de matéria seca da Urochloa ruziziensis.

2. Os três métodos de semeadura, à lanço, à lanço com leve incorporação e em linha, mostram-se adequados para o estabelecimento de braquiária ruziziensis visando à formação de palhada para plantio direto no outono/inverno em região de Cerrado.

3. O herbicida 2,4-D não interferiu no crescimento e produção de massa seca da Urochloa ruziziensis solteira, em áreas de plantio direto, para a comunidade infestante de plantas daninhas pesquisada, independente do método de semeadura.

\section{REFERÊNCIAS BIBLIOGRÁFICAS}

ALVARENGA, R. C.; CABEZAS, W. A. L.; CRUZ, J. C.; SANTANA, D. P. Plantas de cobertura de solo para sistema plantio direto. Informe Agropecuário, Belo Horizonte, v. 22, n. 208, p. 25-36, 2001.

BANZATTO, D. A.; KRONKA, S. N. Experimentação agrícola. 4. ed. Jaboticabal: Funep., 2006. $237 \mathrm{p}$.

BORGHI, E.; CRUSCIOL, C. A. C. Produtividade de milho, espaçamento e modalidade de consorciação com Brachiaria brizantha em sistema plantio direto. Pesquisa Agropecuária Brasileira, Brasília, v. 42, n. 2, p.163-171, 2007.

BRIGHENTI, A. M.; SOBRINHO, F. S.; ROCHA, W. S. D.; MARTINS, C. E.; DEMARTINI, D.; COSTA, T. R. Suscetibilidade diferencial de espécies de braquiária ao herbicida glifosato. Pesquisa Agropecuária Brasileira, Brasília, v. 46, n. 10, p.1241-1246, 2011.

BROWER, J. E.; ZAR, J. H. Field and laboratory methods for general ecology. 2 ed. Dubuque: Wm. C. Brown Company Publishers, 1984. 226 p.

Cultura Agronômica, Ilha Solteira, v.25, n.2, p.175-186, 2016 
CARÁMBULA, M. Pasturas naturales mejoradas. Montevideo: Hemisferio Sur. 1996. 524 p.

EMBRAPA. Centro Nacional de Pesquisa de Solos. Sistema brasileiro de classificação de solos. 2. ed. Rio de Janeiro: EMBRAPA-SPI, 2006. 306 p.

GARCIA, R.; PEREIRA, O. G.; ABREU, J. G.; RUIZ, H. A. Efeito da profundidade de semeadura e da pressão de compactação no solo sobre a emergência de Brachiaria brizantha stapf cv. Marandu. Revista Brasileira de Zootecnia, Viçosa, v. 27, n. 3, p.427-433, 1998.

GIMENES , M. J.; POGETTO, M. F. A. D.; PRADO, E. P.; CHRISTOVAM, R. S.; COSTA, S. I. A.; SOUZA, E. F. C. Interferência de Brachiaria ruziziensis sobre plantas daninhas em sistema de consórcio com milho. Semina: Ciências Agrárias, Londrina, v. 32, n. 3, p.931938, 2011.

IKEDA, F. S.; MITJA, D.; VILELA, L.; CARMONA, R. Banco de sementes no solo em sistemas de cultivo lavoura-pastagem. Pesquisa Agropecuária Brasileira, Brasília, v. 42, n. 11, p.1545-1551, 2007.

JAKELAITIS, A.; SILVA, A. A.; FERREIRA, L. R.; SILVA, A. F.; FREITAS, F. C. L. Manejo de plantas daninhas no consórcio de milho com capim-braquiária (Brachiaria decumbens). Planta Daninha, Viçosa, v. 22, n. 4, p.553-560, 2004.

JAKELAITIS, A.; SILVA, A. F.; SILVA, A. A.; FERREIRA, L. R.; FREITAS, F. C. L.; VIVIAN, R. Influência de herbicidas e de sistemas de semeadura de Brachiaria brizantha consorciada com milho. Planta Daninha, Viçosa, v. 23, n. 1, p.59-67, 2005.

LIMA, S. F.; TIMOSSI, P. C.; ALMEIDA, D. P.; SILVA, U. R. Weed suppression in the formation of brachiarias under three sowing methods. Planta Daninha, Viçosa, v. 32, n. 4, p.699-707, 2014.

MACHADO, L. A. Z.; ASSIS, P. G. G. Produção de palha e forragem por espécies anuais e perenes em sucessão à soja. Pesquisa Agropecuária Brasileira, Brasília, v. 45, n. 4, p.415$422,2010$.

MENEZES, L. A.; LEANDRO, W. M. Avaliação de espécies de coberturas do solo com potencial de uso em sistema de plantio direto. Pesquisa Agropecuária Tropical, Goiânia, v. 34, n. 3, p.173-180, 2004.

NOCE, M. A.; SOUZA, I. F.; KARAM, D.; FRANÇA, A. C.; MACIEL, G. M. Influência da palhada de gramíneas forrageiras sobre o desenvolvimento da planta de milho e das plantas daninhas. Revista Brasileira de Milho e Sorgo, Sete Lagoas, v. 7, n. 3, p.265-278, 2008.

NUNES, U. R.; ANDRADE JÚNIOR, V. C.; SILVA, E. B.; SANTOS, N. F.; COSTA, H. A. O.; FERREIRA, C. A. Produção de palhada de plantas de cobertura e rendimento do feijão em plantio direto. Pesquisa Agropecuária Brasileira, Brasília, v. 41, n. 6, p.943-948, 2006.

PARIZ, C. M.; ANDREOTTI, M.; AZENHA, M. V.; BERGAMASCHINE, A. F.; MELLO, L. M. M.; LIMA, R. C. Massa seca e composição bromatológica de quatro espécies de 
braquiárias semeadas na linha ou a lanço, em consorcio com milho no sistema plantio direto na palha. Acta Scientiarum Animal Sciences, Maringá, v. 32, n. 2, p.147-154, 2010.

PITELLI, R. A.; DURIGAN, J. C. Ecologia das plantas daninhas no sistema plantio direto. In: ROSSELLO, R. D. Siembra directa em el cono sur. Montevideo: PROCISUR, 2001. p. 203-210,

SEVERINO, F. J.; CARVALHO, S. J. P.; CHRISTOFFOLETI, P. J. Interferências mútuas entre a cultura do milho, espécies forrageiras e plantas daninhas em um sistema de consórcio. III - Implicações sobre as plantas daninhas. Planta Daninha, Viçosa, v. 24, n. 1, p.53-60, 2006.

TIMOSSI, P. C.; DURIGAN, J. C.; LEITE, G. J. Formação de palhada por braquiárias para adoção do sistema plantio direto. Bragantia, Campinas, v. 66, n. 4, p.617-622, 2007.

VALLE, C. B.; EUCLIDES, V. P. B.; MACEDO, M. C. M. Características das plantas forrageiras do gênero Brachiaria. In: SIMPÓSIO SOBRE MANEJO DAS PASTAGENS, 17, 2001, Piracicaba. Anais... Piracicaba: FEALQ, 2001. p. 133-176.

VILELA, L.; MARTHA JÚNIOR, G. B.; MACEDO, M. C. M.; MARCHÃO, R. L.; GUIMARÃES JÚNIOR, R.; PULROLNIK, K.; MACIEL, G. A. Sistemas de integração lavoura-pecuária na região do Cerrado. Pesquisa Agropecuária Brasileira, Brasília, v. 46, n. 10, p.1127-1138, 2011.

Cultura Agronômica, Ilha Solteira, v.25, n.2, p.175-186, 2016 
